\title{
A Systematic Review of the Acute Effects of Exercise on Immune and Inflammatory Indices in Untrained Adults
}

William M. C. Brown*, Gareth W. Davison, Conor M. McClean and Marie H. Murphy

\begin{abstract}
Background: Cardiovascular disease (CVD) is the leading cause of global mortality. Although the incidence may be reduced with regular exercise, the health benefits of a single bout of exercise on selected CVD risk factors are not well understood. The primary objective of this review is to consider the transient effects of exercise on immune (neutrophil count) and inflammatory (interleukin-6 [IL-6], C-reactive protein [CRP]) markers in untrained adults.
\end{abstract}

Methods: MEDLINE, EMBASE, CINAHL, Sports Discus and Cochrane were searched for relevant studies published from January 1946 to May 2013. Randomised controlled or crossover studies which measured any of these parameters in untrained but otherwise healthy participants in the $48 \mathrm{~h}$ following about of exercise, less than $1 \mathrm{~h}$ in duration were included.

Results: Ten studies met the inclusion criteria. The results indicate a single bout of aerobic or resistance exercise of moderate to high intensity promotes an increase in IL-6 (145\%) and neutrophil counts (51\%). It appears that 30-60 min of moderate to high intensity exercise is necessary to elicit such changes although variables such as the mode, intensity and pattern of exercise also affect the response. The acute response of CRP within the included studies is equivocal.

Conclusions: Although responses to CRP are inconsistent, a single bout of exercise can increase the activity of both circulating IL-6 and neutrophil counts in untrained adults. These immune and inflammatory responses to a single bout of exercise may be linked to a range of health benefits.

\section{Key Points}

- IL-6 and neutrophil counts increase in response to a bout of aerobic or resistance exercise of moderate to high intensity lasting 30-60 min in duration.

- The acute effect of a single bout of exercise on C-reactive protein is equivocal, and further research is warranted.

- Transient changes in immune and inflammatory markers evoked by a single bout may be linked to the health benefits of regular exercise.

* Correspondence: brown-m@email.ulster.ac.uk

Sport and Exercise Sciences Research Institute, Ulster University, Jordanstown BT37 OQB, Northern Ireland

\section{Background}

Physical inactivity is an established independent risk factor for cardiovascular disease (CVD) [36, 71]. CVD is the major cause of mortality within developed nations and at the forefront of this disease pathology is chronic systemic low-grade inflammation [29]. Characteristically, this state of inflammation permits the secretion of pro-inflammatory cytokines particularly IL-6, tumour necrosis factor (TNF)- $\alpha$ and CRP which are actively involved in insulin resistance and hyperglycaemia [74]. A likely downstream effect of hyperglycaemia is endothelial dysfunction which is associated with a reduction in the bioavailability of vasodilators such as nitric oxide $(\mathrm{NO})[1,13]$ and is often regarded as an initial step in the development of CVD [62]. Such detrimental effects inhibit the key functions of endothelial

\section{空 Springer}


cells, namely modulating vascular tone, and over time may lead to cardiovascular complications [6].

Achieving current physical activity recommendations which encourages daily exercise of at least moderate intensity and accumulating 150 min per week may be an effective strategy to reduce the risk of CVD and other diseases [18]. Regular physical activity promotes many health benefits including improved glucose disposal, reduced blood pressure and favourable changes in the blood lipid profile, all of which have beneficial effects on CVD risk [14, 46]. At any stage, individuals adhering to the physical activity guidelines are likely to be no more than $48 \mathrm{~h}$ from their last bout of physical activity. Therefore, the beneficial adaptations derived from physical activity may be in part, attributed to the short-term or acute changes that occur in the minutes, hours and days following a bout of activity [27]. Thus, a single bout of exercise appears to act as a stimulus for changes which cumulatively are regarded as exercise adaptations.

Physical activity involves the contraction of skeletal muscles [25] which may promote the synthesis and secretion of anti-inflammatory cytokines and peptides from myotubes commonly termed as 'myokines' [56]. Research to date indicates that a single bout of moderate to vigorous intensity aerobic exercise lasting $30-60 \mathrm{~min}$ in duration stimulates muscle-derived IL-6 [26, 35, 48, 49, $65,68]$. However, findings in this area are equivocal with others reporting no transient changes following a bout of exercise [19, 21, 43, 47]. The differing outcomes may be attributed to methodological issues, such as exercise intensity or duration or indeed the individual characteristics of the sample population particularly training status.

Elevated plasma concentrations of muscle-derived IL-6 subsequently initiates the secretion of IL-1 receptor agonist and IL-10 from monocytes and lymphocytes [69]. An increase in the appearance of such antiinflammatory cytokines promotes a range of benefits in vascular reactivity, lipid and glucose metabolism and the suppression of pro-inflammatory cytokines which may reduce the incidence of disease [55]. Exercise-induced changes in IL-6 may also promote an increase in CRP within 24 h of exercise cessation [57]. Although CRP is largely pro-inflammatory, the immediate post-exercise anti-inflammatory actions may also promote endothelial homeostasis by inhibiting cytokines involved in leukocyte activation, proliferation and endothelial dysfunction [57].

The chronic adaptations gained from exercise training are reasonably well established, however, the acute effects have received less attention. Much of the acute effect research to date has focused largely upon either trained or clinical populations, unconventional bouts of activity, testing in the postprandial state or the addition of co-interventions such as antioxidant supplementation.
Therefore, no research to date exists regarding the acute response to a bout of exercise within an untrained population or any discussion of the potential mechanisms that confer anti-inflammatory effects, highlighting a clear gap for this review. Moreover, previous work has arguably focused on studies with modes, intensities and durations of exercise that are largely unachievable and unappealing for members of the general public $[52,54,70]$.

Given that a large proportion of the population could arguably fall into the category of untrained [77], the findings of this review may help to inform future physical activity recommendations to combat the burden of hypokinetic conditions. Delineating this response would also assist in identifying optimal volumes of exercise required to activate anti-inflammatory mechanisms and a range of health benefits that may prevent disease. The purpose of this review was to examine and synthesise the acute effects of exercise with reference to current guidelines on selected immune and inflammatory markers in untrained adults. In addition, this review will proceed to explore the possible novel physiological mechanisms, through which exercise may confer any observed changes.

\section{Methods}

A computerised systematic search was conducted from January 1946 to May 2013 on the following databases: MEDLINE, EMBASE, CINAHL, Sports Discus and Cochrane. The search terms used include 'exercise', 'acute exercise', 'IL-6', 'C-reactive protein', 'neutrophil activation', 'neutrophilia' or 'leukocytosis'. Searching was limited to adult human trials and those in English language. Studies that met the following criteria were included: (i) healthy, untrained and fasted (at least $8 \mathrm{~h}$ ) participants; (ii) a bout of aerobic, anaerobic or resistance exercise less than or equal to $1 \mathrm{~h}$ in duration; (iii) at least one outcome measured in blood prior to and following exercise and (iv) randomised resting controlled or crossover trials. Hand searching of original articles was also performed. Studies analysing the effects of exercise in fasted participants were selected as the postprandial state is a confounding variable known to influence markers of inflammation [39, 51]. Articles were excluded if they reported eccentric exercise or any co-intervention. In addition, studies that classified participants as trained (greater than $2 \mathrm{~h}$ moderate intensity exercise per week or a mean age related $\mathrm{VO}_{2} \max$ greater than excellent as classified by the ACSM [3]) were excluded. The following data was extracted: participant numbers, age, gender, body mass index (BMI), training status, $\mathrm{VO}_{2} \mathrm{max}$, exercise trial details and pre- and postexercise values for the variables of interest (IL-6, CRP and neutrophil counts). Acute messenger ribonucleic acid (mRNA) responses to exercise were deemed to be outside the scope of this review. 


\section{Quality Assessment}

The methodological quality of each study was assessed using the Cochrane Collaboration Handbook (2011). After consulting the specified criteria, a 'low', 'uncertain' or 'high' risk of bias was subjectively assigned to each study for the following: selection, performance, detection, attrition, reporting and other bias. The allocation of risk was affected by the quality of reporting as outlined by Halbert and colleagues [24]. Two authors (WB and MM) assessed the risk of bias independently with any disagreements resolved by consensus.

\section{Results}

\section{Studies Selected}

A PRISMA schematic for the searching strategy is outlined in Fig. 1. Initial searches revealed 96 original articles as possible studies for inclusion. Ten studies met the inclusion criteria and were eligible for inclusion in the current review $[2,4,7,16,28,40,43,50,58,66]$. A summary of each study, including baseline to post-exercise responses, can be observed in Table 1. All studies incorporated a resting control group alongside one or two suitable exercise trials of differing intensity, pattern and/or duration. Two studies had a 'high' risk of bias rating for reporting and other biases, although all remaining studies were categorised as having an 'unclear' or 'low' risk of bias (see Fig. 2).

\section{Participant Characteristics}

Sample populations in the studies included varied from 8 to 23 with an average of 14 participants. Overall, 136 healthy participants were evaluated with 107 undertaking experimental exercise trials and 100 acting as control participants (73 of which acted as their own control). Eight studies examined exclusively male participants, one exclusively female, whilst the remaining study assessed a

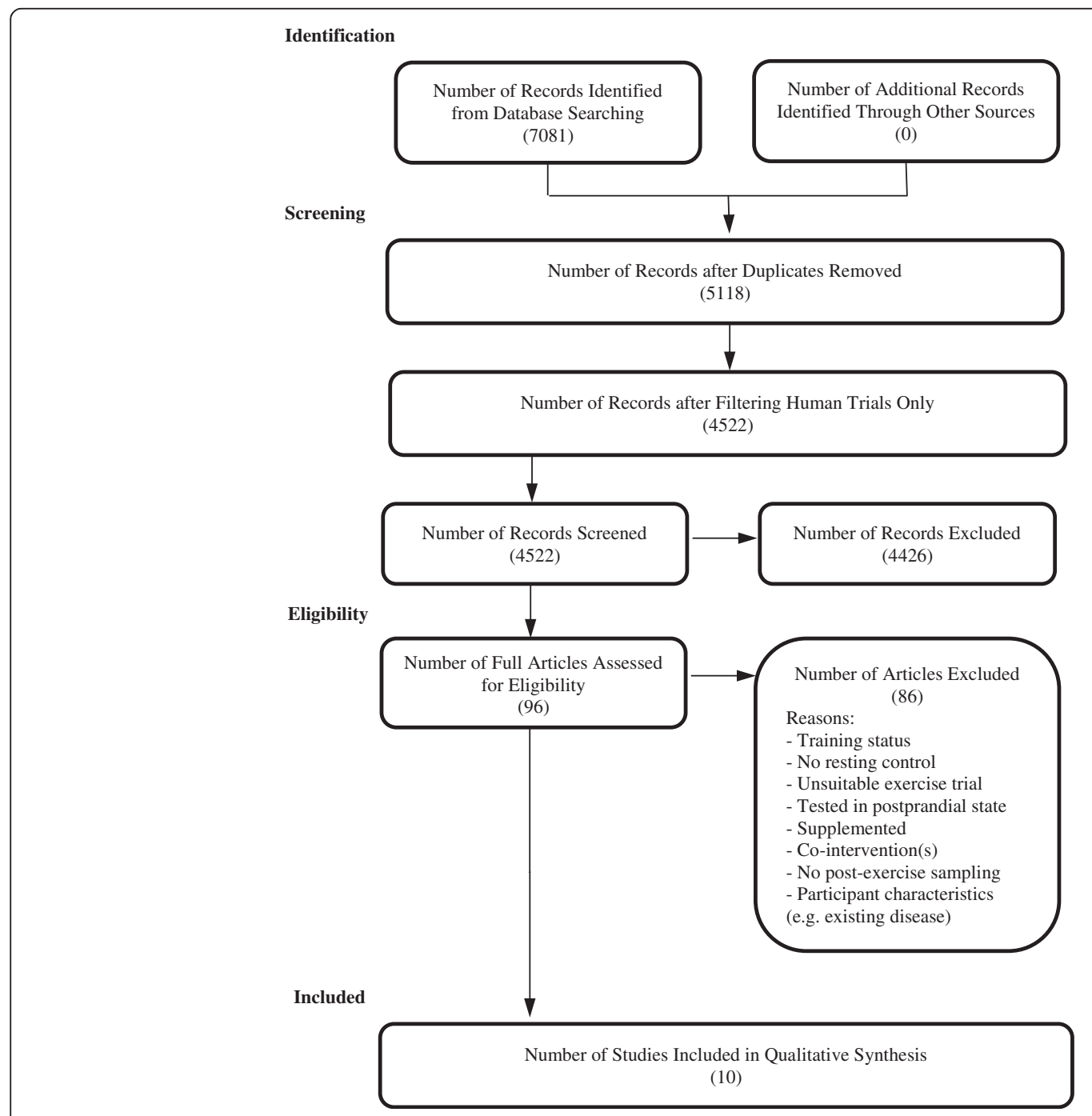

Fig. 1 PRISMA schematic summarising the process of data collection 
Table 1 Summary of acute effects of exercise on inflammatory markers in healthy untrained individuals

\begin{tabular}{|c|c|c|c|c|c|c|c|c|}
\hline \multirow[t]{2}{*}{ Name (year) } & \multirow[t]{2}{*}{ Design } & \multicolumn{3}{|l|}{ Subjects } & \multirow[t]{2}{*}{ Details of exercise trial } & \multirow[t]{2}{*}{ Sample times } & \multirow[t]{2}{*}{ Outcome } & \multirow[t]{2}{*}{ Reported change } \\
\hline & & Group & $n$ (gender) & Age (y) & & & & \\
\hline \multirow[t]{2}{*}{ Nieman et al. (1991) [50] } & \multirow[t]{2}{*}{ RCOT } & Exercise & \multirow[t]{2}{*}{$12(F)$} & \multirow[t]{2}{*}{$36.9 \pm 2.2$} & \multirow[t]{2}{*}{ Walking at $60 \% \mathrm{VO}_{2} \max$ for 45 mins } & \multirow[t]{2}{*}{ Pre, $\mathrm{P} 0$ and $1.5 \mathrm{~h}$} & \multirow[t]{2}{*}{ NC } & \multirow{2}{*}{$\begin{array}{l}\text { Increased from pre to } \mathrm{P} 0 \mathrm{~h} \text { between } \\
\text { groups }\end{array}$} \\
\hline & & Control & & & & & & \\
\hline \multirow[t]{3}{*}{ Brenner et al. (1999) [7] } & \multirow[t]{3}{*}{ RCOT } & Exercise & \multirow[t]{2}{*}{$8(\mathrm{M})$} & \multirow[t]{2}{*}{$24.9 \pm 2.3$} & Cycling at $90 \% \mathrm{VO}_{2}$ max for 5 mins & \multirow{3}{*}{$\begin{array}{l}\text { Pre, } \mathrm{P} 0,3,24 \text { and } \\
72 \mathrm{~h}\end{array}$} & \multirow[t]{3}{*}{ IL-6 } & \multirow{3}{*}{$\begin{array}{l}\text { No change within or between } \\
\text { conditions }\end{array}$} \\
\hline & & Exercise & & & \multirow[t]{2}{*}{$\begin{array}{l}\text { Circuit (5 exercises; } 3 \text { sets } \times 10 \text { reps) at } \\
60-70 \% 1 \text { RM }\end{array}$} & & & \\
\hline & & Control & & & & & & \\
\hline \multirow[t]{2}{*}{ Lyngsø et al. (2002) [40] } & \multirow[t]{2}{*}{ RCT } & Exercise & $9(8 \mathrm{M})$ & $23.6 \pm 0.4$ & \multirow[t]{2}{*}{ Cycling at $60 \% \mathrm{VO}_{2} \max$ for $1 \mathrm{~h}$} & \multirow{2}{*}{$\begin{array}{l}\text { Pre, } \mathrm{P} 0 \text { and every } \\
30 \text { mins to } 3 \mathrm{~h}\end{array}$} & \multirow[t]{2}{*}{ IL-6 } & \multirow{2}{*}{$\begin{array}{l}\text { Increased from Pre at P 0, } 0.5,1.5 \text { and } \\
2 \mathrm{~h} \text { within the exercise condition }\end{array}$} \\
\hline & & Control & $7(5 \mathrm{M})$ & $24.0 \pm 0.3$ & & & & \\
\hline \multirow[t]{2}{*}{ Simonson and Jackson (2004) [66] } & \multirow[t]{2}{*}{$\mathrm{RCT}$} & Exercise & $8(\mathrm{M})$ & $30 \pm 7$ & \multirow{2}{*}{$\begin{array}{l}\text { Resistance ( } 8 \text { exercises; } 3 \text { sets } \times 8-10 \text { reps }) \\
\text { at } 75 \% 1 \text { RM for } 45 \text { mins }\end{array}$} & \multirow{2}{*}{$\begin{array}{l}\text { Pre, } \mathrm{P} 0,15 \text { and } \\
30 \text { mins }\end{array}$} & NC & Increased from Pre to $P$ 0, 15 and 30 \\
\hline & & Control & $8(\mathrm{M})$ & & & & & \\
\hline Højbjerre et al. (2007) [28] & RCOT & Exercise & $16(\mathrm{M})$ & $26.3 \pm 0.8$ & Cycling at $55 \% \mathrm{VO}_{2} \max$ for $1 \mathrm{~h}$ & Pre, P 0 and every & $\mathrm{IL}-6$ & Increased from Pre to $\mathrm{P} 0$ and $2.5 \mathrm{~h}$ \\
\hline & & Control & & $26.0 \pm 0.7$ & & & & withın the exercise group \\
\hline Markovitch et al. (2008) [43] & RCOT & Exercise & $12(\mathrm{M})$ & $54 \pm 4$ & Walking at $50 \% \mathrm{VO}_{2} \max$ for 30 mins & Pre, P $0,2,24,48$ & IL-6, CRP & No change within or between \\
\hline & & Control & & & & 12 and $168 \mathrm{n}$ & & conditions \\
\hline Phillips et al. (2010) [58] & RCOT & Exercise 1 & $14(\mathrm{M})$ & $21.7 \pm 1.7$ & $\begin{array}{l}\text { Resistance exercise ( } 2 \text { sets of } 12 \text { reps at } \\
65 \% 1 \text { RM then } 3 \text { rd set to fatigue) }\end{array}$ & Pre and $\mathrm{P} \mathrm{Oh}$ & IL-6 & $\begin{array}{l}\text { Increased from Pre to } \mathrm{P} 0 \mathrm{~h} \text { with both } \\
\text { intensities compared to control }\end{array}$ \\
\hline & & Exercise 2 & & & $\begin{array}{l}\text { Resistance exercise ( } 2 \text { sets of } 8 \text { reps at } \\
85 \% 1 \text { RM then 3rd set to fatigue) }\end{array}$ & & & \\
\hline & & Control & & & & & & \\
\hline Bizheh and Jaafari (2011) [4] & RCT & Exercise & $14(\mathrm{M})$ & $44.9 \pm 4.1$ & Circuit (10 exercises $\times 3$ sets) at $35 \% 1$ RM & Pre and $\mathrm{P} 0 \mathrm{~h}$ & CRP & Increased from Pre to $\mathrm{P} \mathrm{O} h$ within the \\
\hline & & Control & $9(\mathrm{M})$ & $43.1 \pm 5.2$ & & & & \\
\hline Davison (2011) [16] & RCOT & Exercise & $9(\mathrm{M})$ & $27 \pm 5$ & Cycling Wingate Test $(4 \times 30 \mathrm{~s})$ & Pre, P 0 and & NC & Increased from Pre to $P 0$ and 30 mins \\
\hline & & Control & & & & & & \\
\hline Almada et al. (2013) [2] & RCT & Exercise & $5(\mathrm{M})$ & $20.6 \pm 2.1$ & Running submaximally for 45 mins & Pre and $\mathrm{P} \mathrm{Oh}$ & IL-6 & Increased from Pre to $\mathrm{P} \mathrm{O} \mathrm{h}$ within and \\
\hline & & Control & $5(\mathrm{M})$ & & & & & \\
\hline
\end{tabular}

$R C O T$ randomised crossover trial, $R C T$ randomised control trial, $n$ number of participants, $F$ female, $M$ males, $y$ years of age, mins minutes, 1 RM 1 repetition maximum, $h$ hour(s), Pre pre-exercise, $P$ post-exercise, $N C$ neutrophil count, IL-6 interleukin-6, CRP C-reactive protein 


\begin{tabular}{|c|c|c|c|c|c|c|c|c|c|c|}
\hline & 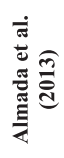 & 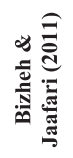 & 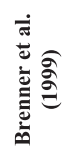 & 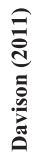 & 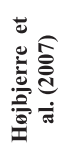 & 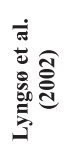 & 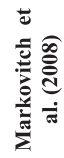 & 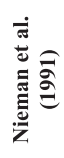 & 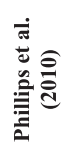 & 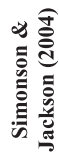 \\
\hline Random sequence generation & $?$ & $?$ & $?$ & Low & $?$ & Low & $?$ & $?$ & $?$ & $?$ \\
\hline Allocation concealment & $?$ & $?$ & $?$ & Low & $?$ & $?$ & $?$ & $?$ & $?$ & $?$ \\
\hline $\begin{array}{l}\text { Blinding of participants and } \\
\text { personnel }\end{array}$ & $?$ & $?$ & $?$ & $?$ & $?$ & $?$ & $?$ & $?$ & $?$ & $?$ \\
\hline Blinding of outcome assessment & $?$ & $?$ & $?$ & $?$ & $?$ & $?$ & $?$ & $?$ & $?$ & $?$ \\
\hline Incomplete outcome data & Low & $?$ & $?$ & $?$ & $?$ & $?$ & Low & $?$ & Low & $?$ \\
\hline Selective reporting & Low & Low & High & Low & Low & Low & Low & Low & Low & Low \\
\hline Other sources of bias & Low & Low & Low & Low & Low & $?$ & Low & Low & High & $?$ \\
\hline
\end{tabular}

Fig. 2 Risk of bias summary for included studies

mixed gender sample. In total, 121 men and 15 women participated in the studies. The mean age of all participants was $31 \pm 11$ years (range, $21-54$ years) whilst mean BMI was $25 \pm 2 \mathrm{~kg} / \mathrm{m}^{2}$ (range, $23-28 \mathrm{~kg} / \mathrm{m}^{2}$ ). Some studies did not directly record individual BMI so this was estimated using reported mean anthropometric measurements. The training status of the participants ranged from sedentary $(n=1)$ or inactive $(n=2)$ to recreationally active $(n=5)$. The training status was not specifically mentioned in two studies but analysis of $\mathrm{VO}_{2}$ max data suggests that the participants were active but not trained. Lastly, in those studies that measured maximal oxygen consumption $(n=7)$, the mean $\mathrm{VO}_{2} \max$ was $37.5 \pm$ $10.3 \mathrm{ml} \cdot \mathrm{kg}^{-1} \cdot \mathrm{min}^{-1}$ (range, $22-49 \mathrm{ml} \cdot \mathrm{kg}^{-1} \cdot \mathrm{min}^{-1}$ ) indicating that all the participants were untrained.

\section{Characteristics of Exercise Trials}

Twelve exercise trials met the inclusion criteria. Four studies examined the impact of aerobic exercise as the sole experimental trial utilising walking $(n=2)$ and cycling $(n=2)$ as the exercise mode with all reporting exercise intensity as a percentage of $\mathrm{VO}_{2} \max$. The mean duration and intensity of the walking trials was $37.5 \mathrm{~min}$ (range, 30-45 min) and $55 \% \mathrm{VO}_{2} \max$ (range, 50-60\% $\mathrm{VO}_{2} \mathrm{max}$ ), respectively. The mean duration and intensity of the cycling trials was $1 \mathrm{~h}$ and $57.5 \% \mathrm{VO}_{2} \max$ (range, 55-60\% $\mathrm{VO}_{2} \mathrm{max}$ ), respectively. Two studies analysed the effects of anaerobic cycling exercise. The mean duration of exercise was $2.5 \mathrm{~min}$ (range, 2-5 min), and the exercise intensity prescribed was equal to or greater than $90 \% \mathrm{VO}_{2} \max$. Five exercise protocols assessed the effects of resistance exercise that focused on all major muscle groups (extremities, core, chest and back) with rest periods between sets. The mean duration of the resistance trials was $28.5 \mathrm{~min}$ (range, $12-45 \mathrm{~min} ; n=2$ [no duration specified in two studies]) with all reporting an exercise intensity related to a percentage of 1 repetition maximum (1RM). Therefore, the mean exercise intensity for resistance trials was $65 \% 1 \mathrm{RM}$ (range, $35-85 \% 1 \mathrm{RM})$. The remaining study analysed the effects of a combined running exercise trial. The total exercise duration was $52 \mathrm{~min}$ (45-min aerobic exercise followed by 7 -min anaerobic exercise), and the exercise intensity was set at $60 \% \mathrm{VO}_{2} \max$ (aerobic) and $90 \%$ $\mathrm{VO}_{2} \max$ (anaerobic), respectively.

\section{Acute IL-6 Response}

Six studies, consisting of eight exercise trials, measured IL-6 in plasma or serum at baseline and either immediately post-exercise or within $5 \mathrm{~min}$. Two studies $[7,43]$ reported no change within or between trials. Conversely, three studies $[2,28,40]$ reported a significant increase within the exercise condition from baseline to postexercise. IL-6 concentrations remained significantly elevated over time within two of these studies as Lyngsø et al. [40] and Højbjerre et al. [28] reported increased concentrations at 2 and $2.5 \mathrm{~h}$ respectively. Two further studies $[2,58]$ reported significant differences between the control and exercise groups post-exercise whereas another study reported no significant differences between conditions [25]. Within those studies that reported changes, the relative increase in IL-6 between baseline and post-exercise was $145 \%$.

\section{Acute CRP Response}

Two studies $[4,43]$ measured serum CRP at baseline and post-exercise. One study [4] reported no difference between exercise and control conditions but observed a significant difference within the exercise group from baseline to post-exercise. The other study [43] reported no significant differences within or between conditions over time.

\section{Acute Neutrophil Response}

Four studies $[16,43,50,66]$ measured changes in neutrophil counts prior to and following exercise. One study [43] 
reported no significant difference within or between conditions from baseline to post-exercise and over time. The remaining three studies reported significant differences from baseline to post-exercise within the exercise trial $[16,66]$ and between $[16,50,66]$ exercise and control conditions. All three studies also reported significant differences over time between conditions at $30 \mathrm{~min}[16,66]$ and $3 \mathrm{~h}$ [50] post-exercise. The relative increase in neutrophil count from baseline to post-exercise was $51 \%$.

\section{Discussion}

This systematic review aimed to consider acute changes in certain immune and inflammatory markers following a bout of exercise in untrained participants. The results suggest that IL-6 and neutrophil counts increase in response to exercise. The post-exercise response of CRP is unclear due to the lack of studies and conflicting findings making firm conclusions difficult to ascertain.

\section{Acute IL-6 Response}

IL-6 was measured in six of the studies reviewed. Four studies, consisting of five exercise trials, reported a significant change in IL-6 from baseline to post-exercise. Almada et al. [2] reported that IL-6 increased from 1.1 $\pm 0.6 \mathrm{pg} / \mathrm{ml}$ at baseline to $2.7 \pm 1.0 \mathrm{pg} / \mathrm{ml}$ immediately post-exercise whilst there was no change within the control group. In agreement, both Højbjerre et al. [28] and Lyngsø et al. [40] reported a similar change in IL-6 which remained elevated for at least $2 \mathrm{~h}$ post-exercise. The remaining crossover study reported the greatest increase in IL-6. Baseline concentrations for both the lower and higher intensity exercise bouts were similar at $2.5 \pm$ 0.4 and $2.8 \pm 0.4 \mathrm{pg} / \mathrm{ml}$, respectively, with post-exercise concentrations of $7.4 \pm 1.3$ and $5.2 \pm 0.7 \mathrm{pg} / \mathrm{ml}$ [58].

The mechanisms behind muscular IL- 6 synthesis and secretion remain unclear although a plausible explanation may be attributable to cellular stress. Kramer and Goodyear [31] suggest that an exercise-induced increase in reactive oxygen species (ROS) augments IL-6 protein secretion and gene transcription in part due to the activation of mitogen-activated protein kinase (MAPK) and $\mathrm{NF}-{ }_{k} \mathrm{~B}$ signalling within skeletal muscle. $\mathrm{NF}{ }_{k} \mathrm{~B}$ is a redox-sensitive transcription factor comprised of five proteins (p50, p52, p65, Rel B and c-Rel), and it exists within the cytoplasm as an inactive heterodimer whilst bound to the inhibitory subunit IkB [59]. Increased concentrations of ROS can activate IkB- $\alpha$ kinase (IKK) which results in the phosphorylation and degradation of IkB allowing $\mathrm{NF}_{{ }_{\mathrm{K}}} \mathrm{B}$ subunits to dimerise, promoting nuclear translocation and possibly cytokine gene expression [60]. ROS have been identified as important modulators of cell signalling and they have been shown to increase following a single bout of aerobic exercise [17] possibly due to mitochondrial electron leakage, enhanced neutrophil recruitment, catecholamine auto-oxidation and the involvement of several enzymes including NADPH oxidase, xanthine oxidase and phospholipase $A_{2}[23,59]$. Similarly, it has been shown that NF- ${ }_{\kappa} \mathrm{B}$ transiently increases in response to a single bout of intense resistance exercise in humans [76]. Although entirely speculative, it is possible that an accumulation of ROS could activate $\mathrm{NF}_{-} \mathrm{B}$ however, more research is required to support this hypothesis. No study within this review directly measured ROS and $\mathrm{NF}_{{ }_{\mathrm{K}}} \mathrm{B}$, but it may be possible that the exercise stimulus adopted may have provided ideal conditions for the formation of ROS and downstream increases in IL-6.

The exercise stimulus, particularly exercise duration and intensity has often been cited as key elements in stimulating IL-6 synthesis and secretion by skeletal muscles $[53,57]$. Three out of the four studies that reported significant differences in IL- 6 employed aerobic exercise protocols lasting approximately $1 \mathrm{~h}$ in duration. In addition to the exercise stimulus, the muscle mass recruited and physical fitness have also been postulated to affect plasma IL-6 concentrations [57]. As the participants are untrained, the extended duration and intensity of exercise may promote a reduction or depletion in intramuscular glycogen. Untrained skeletal muscles are less adept at conserving glycogen stores, and as a consequence, this stimulates the upregulation of IL-6 expression [30] possibly in some part due to the enhanced activity of AMP-activated protein kinase (AMPK) [41] or skeletal muscle mRNA expression. Louis et al. [38] and Buford et al. [8] confirmed this by reporting increased IL6 mRNA expression following a single bout of moderate to vigorous intensity exercise in recreationally active participants. Therefore, enhanced gene expression may result in the observed increase in plasma concentrations of the functional IL-6 protein. The remaining study that reported post-exercise changes assessed the IL- 6 response to both high-intensity low-volume and low-intensity high-volume resistance exercise. The results from this study indicate that a greater exercise volume promotes a greater increase in IL-6 concentration although the exercise mode and intensity is also a contributory factor.

Although the precise mechanisms remain unclear, an increase in circulating IL-6 following exercise is an important physiological response, and it has been suggested that IL-6 has many biological functions. A downstream health benefit of a transient increase in muscle-derived IL- 6 is an increase in glucose and lipid metabolism [22, 55]. Carey and colleagues [12] reported that infusion of rhIL-6 increased the phosphorylation of AMPK in healthy humans and stimulated glucose disposal and GLUT-4 translocation. In addition, AMPK phosphorylates acetyl-CoA carboxylase (ACC) which in turn decreases malonyl CoA and removes the inhibition on carnitine palmitoyltransferase (CPT)-1 resulting in fatty acid oxidation 
[72]. Such benefits promote greater metabolic control and may assist in reducing the incidence of metabolic disease over time. Moreover, a transient increase in exercise-induced IL-6 seems to have an inhibitory effect on the activity of pro-inflammatory cytokines particularly TNF- $\alpha$ and IL-1 $\beta$ [57]. IL- 6 is believed to stimulate a cascade of anti-inflammatory cytokines and receptors particularly IL-10 alongside TNF- $\alpha$ and IL- 1 receptors which subsequently neutralise these potent proinflammatory cytokines [57]. This response prevents TNF- $\alpha$ from interfering in insulin signalling and may prevent hyperglycaemia and metabolic disorder [57].

In contrast, two studies reported no significant differences in IL-6 from baseline to post-exercise. These conflicting findings may be attributed to various methodological issues. Both studies recruited relatively small sample sizes ( $n=8$ [7] and 12 [43]) possibly resulting in a lack of statistical power. Additionally, the exercise stimulus adopted may be responsible for the lack of difference within the findings. As previously indicated, IL6 upregulation is dependent upon exercise intensity and duration, but Markovitch et al. [43] employed 30 min of moderate intensity exercise $\left(50 \% \mathrm{VO}_{2} \max \right)$ whilst Brenner et al. [7] examined both a moderate intensity circuit trial equivalent to $50 \% \mathrm{VO}_{2} \max$ and short-duration high-intensity cycling $(5 \mathrm{~min})$ which may not be of sufficient intensity to evoke an antiinflammatory response.

\section{Acute CRP Response}

CRP is an independent marker of CVD risk, and it was measured in two of the studies reviewed. Bizheh and Jaafari [4] reported that CRP increased from $1.98 \pm$ $0.46 \mathrm{mg} / \mathrm{l}$ at baseline to $2.67 \pm 0.5 \mathrm{mg} / \mathrm{l}$ post-exercise whilst there was no change within the control group. Conversely, Markovitch et al. [43] reported no change in CRP following exercise. The equivocal findings between the two studies may be attributed to numerous methodological factors though the only apparent differences lie in the exercise stimulus and the percentage body fat of the participants involved.

CRP is an acute phase reactant that tends to only increase (within the exercise model) following a strenuous or prolonged bout of exercise or exercise resulting in muscular injury [5, 64]. This challenges the findings of Bizheh and Jaafari [4] as a low-intensity resistance exercise protocol was employed and supports the results reported by Markovitch et al. [43] as daily accustomed moderateintensity exercise should not present increases in CRP. In agreement, studies ineligible for inclusion in the current review adopted similar exercise protocols and participants but reported no change in CRP immediately following and up to $24 \mathrm{~h}$ post-exercise [15, 32, 44, 47]. A possible explanation for the rise in CRP reported by Bizheh and
Jaafari [4] may be that the resistance protocol induced muscular damage as the participants are untrained and may be unaccustomed to this mode of physical exertion. CRP plays a key role in recognising pathogens and cell debris so increased concentrations may be linked to the leakage of muscular components into circulation [5]. An alternative mechanism responsible for exercise-induced increases in CRP may be the parallel increase in antiinflammatory cytokines. An increase in IL-6 is thought to promote the hepatic synthesis and secretion of CRP [5] although only one of the two studies measured IL- 6 and reported no changes so it is difficult to determine the exact mechanism responsible.

Lin and colleagues [37] have demonstrated that an increase in CRP is strongly associated with percentage of body fat mass, and this association is linked to increased adipose tissue. Adipose tissue secretes several adipokines which mediate inflammation and promote the hepatic synthesis of CRP and release into circulation [57]. The mean percentage body fat for participants recruited by Bizheh and Jaafari [4] was $26.3 \pm 4.4 \%$ (exercise group) and $28.2 \pm 5.4 \%$ (control) whereas the mean for participants recruited by Markovitch et al. [43] was $22 \pm 2 \%$. Consequently, this apparent difference may account for the conflicting concentration of CRP between the two studies following a single bout of exercise.

\section{Acute Neutrophil Response}

Blood neutrophil count was measured in four of the studies reviewed. Nieman et al. [50] reported neutrophil counts increased from $3.99 \pm 0.21 \times 10^{9}$ cells $\cdot \mathrm{L}^{-1}$ at baseline to $5.36 \pm 0.41 \times 10^{9}$ cells $\mathrm{L}^{-1}$ immediately postexercise. Simonson and Jackson [66] reported a similar increase in neutrophils following resistance exercise which remained elevated for $30 \mathrm{~min}$. In agreement, Davison [16] reported that neutrophil count increased from $2.3 \pm 0.7 \times 10^{9}$ cells $\cdot \mathrm{L}^{-1}$ at baseline to $4.0 \pm 1.5 \times 10^{9}$ cells $\cdot \mathrm{L}^{-1}$ following a bout of high intensity exercise which also remained elevated for $30 \mathrm{~min}$. This response appears to be a common finding as ineligible studies for the current review have also reported increased neutrophil counts following aerobic and maximal bouts of exercise in similarly untrained participants $[42,61]$. The increase in blood neutrophil counts appears to be less sensitive to the exercise stimulus as a similar response is evident across a range of intensities, durations and exercise modes.

Neutrophils are the primary leukocyte subpopulation to arrive at damaged or stressed tissue sites [9]. Previously, it was thought that the increase in the number of neutrophil cells is directly linked to exercise-induced muscular damage although similar observations have been reported following non-damaging exercise [68]. Therefore, the likely mechanisms responsible for this increase are multifactorial 
and may include an increase in the release of various biochemical products such as catecholamine's or alternatively enhanced cell signalling or blood flow [9].

Skeletal muscles can recruit neutrophils via cytokine signalling, but once they penetrate the cell membrane, neutrophils engage in phagocytosis commonly referred to as the 'respiratory burst'. Activated neutrophils produce a range of ROS including superoxide $\left(\mathrm{O}_{2}^{--}\right)$and undergo a process of degranulation [23]. Antioxidant enzymes reduce the potency of $\mathrm{O}_{2}^{--}$by dismutating it to hydrogen peroxide, $\left(\mathrm{H}_{2} \mathrm{O}_{2}\right)$ but in the presence of myeloperoxidase, a degranulation enzyme, another potent oxidant is produced in the form of hypochlorous acid (HOCl) [63]. This suggests that increased cell counts of neutrophils may be undesirable for cardiovascular health as they have been implicated in cellular damage and endothelial dysfunction via an oxidative stress mechanism. Alternatively, increased neutrophil cell recruitment following exercise may also have beneficial effects upon health, as they are involved in muscular regeneration possibly via the activation of satellite cells and their recruitment usually activates other immune cell subpopulations such as lymphocytes [49]. An increase in the recruitment of such cells following exercise promotes the upregulation of anti-inflammatory gene expression and proteins, particularly IL-1 receptors [10] which suppress the pro-inflammatory cytokine IL-1 $\beta$. In addition, $\mathrm{H}_{2} \mathrm{O}_{2}$ is now recognised as an important signalling molecule if it can avoid decomposition by antioxidants $[20,75]$ and it may be important for exercisederived health benefits particularly those relating to the modulation of endothelial cell function [11].

In contrast, Markovitch et al. [43] reported no change in neutrophils following moderate intensity aerobic exercise. This may be attributed to the exercise stimulus however, an ineligible study by Nieman and colleagues [49] adopted a similar experimental trial and reported a significant increase in neutrophil counts immediately post-exercise. Although the differing number of participants or alternatively the slightly greater exercise volume employed (60\% $\mathrm{VO}_{2} \mathrm{max}$ ) may account for this discrepancy in neutrophil cell recruitment.

\section{Limitations}

The systematic review presented is not without limitations. Studies favoured male participants as the sample population and as such, the results are more generalised to this specific gender. The choice to select male participants may be influenced by the biochemical effects of the menstrual cycle [67], and researchers may have wished to avoid these complications by selecting a convenience sample. Nevertheless, it is not implausible to suggest that similar immune and inflammatory health benefits might accrue for females undertaking similar bouts of exercise.
A further limitation was the concept of 'untrained' participants, as this was difficult to define. Some studies used terminology such as 'sedentary' or 'inactive' to describe the participant training status whereas others used 'physically' or 'recreationally active'. The inclusion criteria for training status was set at less than or equal to $2 \mathrm{~h}$ as less than half the UK adult population achieve recommended activity levels [73]. This postulates that the results are more representative of typical physical activity patterns. It was important to distinguish the training status as previous reports have shown an inverse relationship between physical fitness and certain markers of inflammation [33, 34].

Finally, the studies included adopted differing exercise protocols in terms of mode, duration and intensity as well as the timing of post-exercise sampling. This means that it is difficult to draw consistent conclusions with regard to the exact physical activity recommendations necessary to elicit the health benefits discussed. Furthermore, the acute health benefits associated with a single bout of exercise and the proposed physiological mechanisms explored within this review are speculative and further research is warranted.

\section{Recommendations for Future Research}

Despite an increase in the number of studies looking at the association between exercise and health, the transient health benefits of exercise remain poorly understood. Future studies should address the paucity of research examining female participants as well as the lack of randomised control or crossover trials incorporating a 'true' resting control. Tackling both these issues will provide an insight into the beneficial or detrimental effects of a single bout of exercise on CVD risk factors in females and whether any health benefits conferred are solely attributed to exercise. In order to resolve these issues, researchers should carefully devise and implement robust study designs accounting for the main confounding variables, which may serve to elucidate the specific contribution of individual bouts of exercise to overall health.

In addition, the exercise characteristics or stimuli should gain more focus, as this inevitably provides the stress that promotes the acute responses. Future research should explore the effects of differing exercise intensities and durations possibly across different populations and how these relate to transient changes in immune cells, cytokine concentrations and endothelial function. Equally, the mode of exercise warrants further investigation to clarify any differences between aerobic and resistance methods and which promotes the greatest benefits. Moreover, it may also be of interest to evaluate the impact of exercise trials tailored for members of the general public. Walking has previously been described as the cornerstone of physical activity interventions and yet the acute health benefits gained from 
this type of activity are not fully understood [45]. Establishing optimal doses of exercise that augment a range of health benefits may inform physical activity prescription guidelines and possibly reduce the incidence of disease.

Additionally, further research is required to elucidate the time course of acute exercise-induced responses. In order to accomplish this, researchers should incorporate the use of multiple post-exercise measurements within the study design. Not only will this allow the tracking of markers but may also contribute to the identification of optimal measurement times. Finally, future investigations should also attempt to clarify the physiological mechanisms whereby acute responses in skeletal muscle-derived cytokines relate to exercise training adaptations and health in general. A potential strategy for accomplishing this may be to assess multiple accepted markers of cardiovascular health particularly those involved in cell signalling, metabolism and gene expression.

\section{Conclusions}

A single bout of either aerobic or resistance exercise with a moderate to vigorous/high intensity promotes an increase in systemic concentrations of muscle-derived IL-6 and circulating neutrophil counts. The health benefits achieved from this IL- 6 response assist in the clearance of glucose and lipoproteins from circulation and improve insulin sensitivity and may prevent the initiation and development of CVD as both macronutrients are integral in the development of the fatty streak and atherosclerotic plaque. Accordingly, physical activity recommendations may encourage untrained adults to undertake bouts of moderate to vigorous aerobic or resistance exercise greater than $30 \mathrm{~min}$ in duration. More parallel research is required to establish the effects on CRP as there is a lack of evidence and conflicting findings.

\section{Competing interests}

The authors declare that they have no competing interests.

\section{Authors' contributions}

The design of the systematic review was devised by WB, GD, CM and MM. The collection and synthesis of the data was undertaken by WB. The risk of bias assessment was completed by WB and MM. Data interpretation and manuscript preparation was completed by WB, GD, CM and MM. All authors read and approved the final version of the manuscript.

\section{Acknowledgements}

William M. C. Brown received a Vice Chancellor's Research Scholarship (VCRS) from Ulster University to conduct this study and in preparation of this manuscript.

Received: 4 September 2015 Accepted: 15 September 2015

Published online: 20 October 2015

\section{References}

1. Allen JD, Cobb FR, Kraus WE, Gow AJ. Total nitrogen oxide following exercise testing reflects endothelial function and discriminates health status. Free Radic Biol Med. 2006;41(5):740-7.

2. Almada C, Cataldo LR, Smalley SV, Diaz E, Serrano A, Hodgson MI, et al. Plasma levels of interleukin-6 and interleukin-18 after an acute physical exercise: relation with post-exercise energy intake in twins. J Physiol Biochem. 2013;69(1):85-95.

3. American College of Sports Medicine. ACSM's guidelines for exercise testing and prescription. 8th ed. Philadelphia: Lippincott Williams \& Wilkins; 2010.

4. Bizheh $\mathrm{N}$, Jaafari $\mathrm{M}$. The effect of a single bout circuit resistance exercise on homocysteine, hs-CRP and fibrinogen in sedentary middle aged men. Iran J Basic Med Sci. 2011;14(6):568-73.

5. Black S, Kushner I, Samols D. C-reactive protein. J Biol Chem. 2004;279(47):48487-90.

6. Bonetti PO, Lerman LO, Lerman A. Endothelial dysfunction a marker of atherosclerotic risk. Arterioscler Thromb Vasc Bio. 2003;23:168-75.

7. Brenner IKM, Natale VM, Vasiliou P, Moldoveanu Al, Shek PN, Shephard RJ. Impact of three different types of exercise on components of the inflammatory response. Eur J Appl Occup Physiol. 1999;80(5):452-60.

8. Buford TW, Cooke MB, Willoughby DS. Resistance exercise-induced changes of inflammatory gene expression within human skeletal muscle. Eur J Appl Physiol. 2009;107:463-71.

9. Butterfield TA, Best TM, Merrick MA. The dual roles of neutrophils and macrophages in inflammation: a critical balance between tissue damage and repair. J Athl Train. 2006;41(4):457-65.

10. Büttner $P$, Mosig $S$, Lechtermann $A$, Funke $H$, Mooren FC. Exercise affects the gene expression profiles of human white blood cells. J Appl Physiol. 2006;102:26-36.

11. Cai H. Hydrogen peroxide regulation of endothelial function: origins, mechanisms, and consequences. Cardiovasc Res. 2005;68(1):26-36.

12. Carey AL, Steinberg GR, Macaulay SL, Thomas WG, Holmes AG, Ramm G, et al. Interleukin-6 increases insulin-stimulated glucose disposal in humans and glucose uptake and fatty acid oxidation in vitro via AMP-activated protein kinase. Diabetes. 2006;55(10):2688-97.

13. Ceriello A, Motz E. Is oxidative stress the pathogenic mechanism underlying insulin resistance, diabetes, and cardiovascular disease? The common soil hypothesis revisited. Arterioscler Thromb Vasc Biol. 2004;24(5):816-23.

14. Coleman KJ, Raynor HR, Mueller DM, Cerny FJ, Dorn JM, Epstein LH. Providing sedentary adults with choices for meeting their walking goals. Prev Med. 1999:28(5):510-19.

15. Davis J, Murphy M, Trinick T, Duly E, Nevill A, Davison G. Acute effects of walking on inflammatory and cardiovascular risk in sedentary postmenopausal women. J Sports Sci. 2008;26(3):303-09.

16. Davison $\mathrm{G}$. Innate immune responses to a single session of sprint interval training. Appl Physiol Nutr Metab. 2011;36:395-404.

17. Davison GW, Ashton T, McEneny J, Young IS, Davies B, Bailey DM. Critical difference applied to exercise-induced oxidative stress: the dilemma of distinguishing biological from statistical change. J Physiol Biochem. 2012:68:377-84.

18. Department of Health. Start active, stay active: a report on physical activity $<$ ?show [?A3B2 twb=.27w?]?><? show [?A3B2 tlsb=-.09pt?]?> from the four home countries' Chief Medical Officers. Dep Health. 2011:3-59.

19. Fatouros I, Chatzinikolaou A, Paltoglou G, Petridou A, Avloniti A, Jamurtas A, et al. Acute resistance exercise results in catecholaminergic rather than ypothalamic-pituitary-adrenal axis stimulation during exercise in young men. Stress: Int J Biol Stress. 2010;13(6):461-68.

20. Forman $\mathrm{HJ}$, Maiorino M, Ursini F. Signalling functions of reactive oxygen species. Biochem. 2010;49(5):835-42

21. García JJ, Bote E, Hinchado MD, Ortega E. A single session of intense exercise improves the inflammatory response in healthy sedentary women. J Physiol Biochem. 2011;67:87-94.

22. Glund S, Krook A. Role of interleukin-6 signalling in glucose and lipid metabolism. Acta Physiol. 2008;192(1):37-48.

23. Gomes EC, Silva AN, Oliveira MR. Oxidants, antioxidants, and the beneficial roles of exercise-induced production of reactive species. Oxid Med Cell Longev. 2012. http://www.hindawi.com/journals/oximed/2012/756132/abs/. Accessed 12 Sept 2013.

24. Halbert JA, Silagy CA, Finucane P, Withers RT, Hamdorf PA. Exercise training and blood lipids in hyperlipidemic and normolipidemic adults: a metaanalysis of randomised controlled trials. Eur J Clin Nutr. 1999:53:514-22.

25. Hardman AE, Stensel DJ. Physical activity and health: the evidence explained. 2nd ed. Oxon: Routledge; 2009.

26. Harris RA, Padilla J, Hanlon KP, Rink LD, Wallace JP. The flow-mediated dilation response to acute exercise in overweight active and inactive men. Obesity. 2008;16(3):578-84. 
27. Haskell WL. Health consequences of physical activity: understanding and challenges regarding dose-response. Med Sci Sports Exerc. 1994;26(6):649-60.

28. Højbjerre L, Rosenzweig M, Dela F, Bruun JM, Stallknecht B. Acute exercise increases adipose tissue interstitial adiponectin concentration in healthy overweight and lean subjects. Eur J Endocrinol. 2007;157(5):613-23.

29. Hotamisligil GS. Inflammation and metabolic disorders. Nature. 2006;444:860-7.

30. Keller C, Steensberg A, Hansen AK, Fischer CP, Plomgaard P, Pedersen BK. Effect of exercise, training, and glycogen availability on IL-6 receptor expression in human skeletal muscle. J Appl Physiol. 2005;99:2075-9.

31. Kramer HF, Goodyear LJ. Exercise, MAPK, and NF-KB signaling in skeletal muscle. J Appl Physiol. 2007;103(1):388-95.

32. Krüger K, Agnischock S, Lechtermann A, Tiwari S, Mishra M, Pilat C, et al. Intensive resistance exercise induces lymphocyte apoptosis via cortisol and glucocorticoid receptor-dependent pathways. J Appl Physiol. 2011;110:1226-32.

33. Kullo IJ, Khaleghi M, Hensrud DD. Markers of inflammation are inversely associated with $\mathrm{VO}_{2}$ max in asymptomatic men. J Appl Physiol. 2007;102:1374-79

34. LaMonte MJ, Durstine JL, Yanowitz FG, Lim T, DuBose KD, Davis P, et al. Cardiorespiratory fitness and C-reactive protein among a tri-ethnic sample of women. Circ. 2002;106:403-6.

35. Leggate M, Nowell MA, Jones SA, Nimmo MA. The response of interleukin-6 and soluble interleukin-6 receptor isoforms following intermittent high intensity and continuous moderate intensity cycling. Cell Stress and Chaperones. 2010;15(6):827-33.

36. Leung FP, Yung LM, Laher I, Yao X, Chen ZY, Huang Y. Exercise, vascular wall and cardiovascular diseases. Sports Med. 2008;38(12):1009-24.

37. Lin C-C, Kardia S, Li C-I, Liu C-S, Lai M-M, Lin W-Y, et al. The relationship of high sensitivity $C$-reactive protein to percent body fat mass, body mass index, waist-to-hip ratio, and waist circumference in a Taiwanese population. BMC Public Health. 2010;10:579.

38. Louis E, Raue U, Yang Y, Jemiolo B, Trappe S. Time course of proteolytic, cytokine, and myostatin gene expression after acute exercise in human skeletal muscle. J Appl Physiol. 2007;103:1744-51.

39. Lundman P, Boquist S, Samnegård A, Bennermo M, Held C, Ericsson C-G, et al. A high-fat meal is accompanied by increased plasma interleukin-6 concentrations. Nutr Metab Cardiovasc Diseases. 2007;17:195-202.

40. Lyngsø D, Simonsen L, Bülow J. Interleukin-6 production in human subcutaneous abdominal adipose tissue: the effect of exercise. J Physiol. 2002;543(1):373-78.

41. MacDonald C, Wojtaszewski JF, Pedersen BK, Kiens B, Richter EA. Interleukin6 release from human skeletal muscle during exercise: relation to AMPK activity. J Appl Physiol. 2003;95:2273-7.

42. Magalhães J, Ferreira R, Marques F, Olivera E, Soares J, Ascensão A. Indoor climbing elicits plasma oxidative stress. Med Sci Sports Exerc. 2007;39(6):955-63.

43. Markovitch D, Tyrrell RM, Thompson D. Acute moderate-intensity exercise in middle-aged men has neither an anti-nor proinflammatory effect. J Appl Physiol. 2008;105(1):260-65.

44. Mendham AE, Donges CE, Liberts EA, Duffield R. Effects of mode and intensity on the acute exerciseinduced $I L-6$ and CRP responses in a sedentary, overweight population. Eur J Appl Physiol. 2011;111(6):1035-45.

45. Morris JN, Hardman AE. Walking to health. Sports Med. 1997;23(5):306-32.

46. Murphy M, Nevill A, Neville C, Biddle S, Hardman A. Accumulating brisk walking for fitness, cardiovascular risk, and psychological health. Med Sci Sports Exerc. 2002;34(9):1468-74.

47. Murtagh EM, Boreham C, Nevill A, Davison G, Trinick T, Duly E, et al. Acute responses of inflammatory markers of cardiovascular disease risk to a single walking session. J Physical Activity \& Health. 2005;3:324-32.

48. Newlin MK, Williams S, McNamara T, Tjalsma H, Swinkels DW, Haymes EM. The effects of acute exercise bouts on hepcidin in women. Int J Sports Nutr Exerc Metab. 2012;22:79-88.

49. Nieman DC, Henson DA, Austin MD, Brown VA. Immune response to a 30-minute walk. Med Sci Sports Exerc. 2005;37(1):57-62

50. Nieman DC, Nehlsen-Cannarella SL, Donohue KM, Chritton DB, Haddock $\mathrm{BL}$, Stout RW, et al. The effects of acute moderate exercise on leukocyte and lymphocyte subpopulations. Med Sci Sports Exerc. 1991;23(5):578-85.

51. O'Keefe JH, Bell DSH. Postprandial hyperglycaemia/hyperlipidaemia (postprandial dysmetabolism) is a cardiovascular risk factor. Am J Cardiol. 2007;100:899-904.
52. Ostrowski K, Rohde T, Asp S, Schjerling P, Pedersen BK. Pro- and antiinflammatory cytokine balance in strenuous exercise in humans. J Physiol. 1999;515:287-91.

53. Ostrowski K, Rohde T, Asp S, Schjerling P, Pedersen BK. Chemokines are elevated in plasma after strenuous exercise in humans. Eur J Appl Physiol. 2001;84(3):244-45.

54. Paulsen G, Benestad HB, Strøm-Gundersen I, Mørkrid L, Lappegård KT, Raastad T. Delayed leukocytosis and cytokine response to high-force eccentric exercise. Med Sci Sports Exerc. 2005;37(11):1877-83.

55. Pedersen BK, Steensberg A, Keller P, Keller C, Fischer C, Hiscock N, et al. Muscle-derived interleukin-6: lipolytic, anti-inflammatory and immune regulatory effects. Pflüg Arch. 2003;446(1):9-16.

56. Pedersen BK, Åkerström TCA, Nielsen AR, Fischer CP. Role of myokines in exercise and metabolism. J Appl Physiol. 2007;103:1093-8.

57. Petersen AMW, Pedersen BK. The anti-inflammatory effect of exercise. J App Physiol. 2005;98(4):1154-62.

58. Phillips MD, Flynn MG, McFarlin BK, Stewart LK, Timmerman KL. Resistance training at eight-repetition maximum reduces the inflammatory milieu in elderly women. Med Sci Sports Exerc. 2010;42(2):314-25.

59. Powers SK, Jackson MJ. Exercise-induced oxidative stress: cellular mechanisms and impact on muscle force production. Physiol Rev. 2008;88(4):1243-76.

60. Powers SK, Talbert EE, Adhihetty PJ. Reactive oxygen and nitrogen species as intracellular signals in skeletal muscle. J Physiol. 2011;589(9):2129-38.

61. Quindry JC, Stone WL, King J, Broeder CE. The effects of acute exercise on neutrophils and plasma oxidative stress. Med Sci Sports Exerc. 2003;35(7):1139-45.

62. Ross R. The pathogenesis of atherosclerosis: a perspective for the 1990s. Nature. 1993;362(6423):801-09.

63. Sachdev S, Davies KJ. Production, detection, and adaptive responses to free radicals in exercise. Free Radic Biol Med. 2008:44:215-23.

64. Scharhag J, Meyer T, Gabriel HHW, Schlick B, Faude O, Kindermann W. Does prolonged cycling of moderate intensity affect immune cell function? Br J Sports Med. 2005;39:171-7.

65. Scott JPR, Sale C, Greeves JP, Casey A, Dutton J, Fraser WD. Effect of exercise intensity on the cytokine response to an acute bout of running. Med Sci Sports Exerc. 2011;43(12):2297-306.

66. Simonson SR, Jackson CG. Leukocytosis occurs in response to resistance exercise in men. J Strength Cond Res. 2004;18(2):266-71.

67. Skafar DF, Xu R, Morales J, Ram J, Sowers JR. Female sex hormones and cardiovascular disease in women. J Clin Endocrinol Metab. 1997;82(12):3913-8.

68. Sorichter S, Martin M, Julius P, Schwirtz A, Huonker M, Luttman W, et al. Effects of unaccustomed and accustomed exercise on the immune response in runners. Med Sci Sports Exerc. 2006;38(10):1739-45.

69. Steensberg A, Fischer CP, Keller C, Møller K, Pedersen BK. IL-6 enhances plasma IL-1ra, IL-10, and cortisol in humans. Am J Physiol Endocrinol Metab. 2003;285(2):e433-7.

70. Suzuki K, Nakaji S, Yamada M, Liu Q, Kurakake S, Okamura N, et al. Impact of a competitive marathon race on systemic cytokine and neutrophil responses. Med Sci Sports Exerc. 2003;35(2):348-55.

71. Thompson PD, Lim V. Physical activity in the prevention of atherosclerotic coronary heart disease. Curr Treat Options Cardiovasc Med. 2003;5:279-85.

72. Thomson DM, Winder WW. AMP-activated protein kinase control of fat metabolism in skeletal muscle. Acta Physiol. 2009;196(1):147-54.

73. Townsend N, Bhatnagar P, Wickramasinghe K, Scarborough P, Foster C, Rayner M. Physical activity statistics 2012. London: British Heart Foundation; 2012.

74. Van Gaal LF, Mertens IL, Christophe E. Mechanisms linking obesity with cardiovascular disease. Nature. 2006:444:875-80.

75. Veal EA, Day AM, Morgan BA. Hydrogen peroxide sensing and signalling. Mol Cell. 2007;26(1):1-14.

76. Vella L, Caldow MK, Larsen AE, Tassoni D, Della Gatta PA, Gran P, et al. Resistance exercise increases NF-kB activity in human skeletal muscle. Am J Physiol Regul Integr Comp Physiol. 2011;302(6):R667-73.

77. World Health Organisation. Prevalence of insufficient physical activity. In: Global Health Observatory Data. 2015. http://www.who.int/gho/ncd/ risk_factors/physical_activity_text/en/. Accessed 13 Mar 2015. 